\title{
EKSTRAKSI PASIR SILIKAT (SILLICOND SAND) SEBAGAI MATERIAL SUBTRAT PADA SENSOR GAS DAN TURUNANNYA
}

\author{
Tossin Alamsyah $^{1 \otimes}$, Dewa Putu Hermida ${ }^{2}$ \\ ${ }^{I}$ Teknik Elektro, Program Magister Terapan Teknik Elektro, Politeknik Negeri Jakarta, Kampus \\ Universitas Indonesia Depok, 16421 \\ ${ }^{2}$ Puslit Elektronika dan Telekomunikasi LIPI, Jl. Cisitu 21/154 D, Bandung - 40135

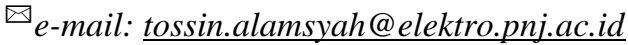

\begin{abstract}
Silica sand is a material from crystalline silica (SiO2) and other compounds containing other materials during the deposition process, having a combined composition of $\mathrm{SiO} 2, \mathrm{Fe} 2 \mathrm{O3}, \mathrm{Al2O} 3, \mathrm{CaO}, \mathrm{MgO}$, and K2O. Sensitivity ((Si) of the gas sensor is influenced by the porosity (Ø) of the surface of the substrate, generally the substrate material of the gas sensor is used alumina (Al2O3) or dioxside silicon (SiO2). This article discusses the results of the sintering process on silica sand which aims to obtain the structure $\mathrm{SiO} 2$ is good, on theparameter thermal resistivity (RT). The sintering process is carried out on silica sand with a mixture of aluminum sulfate (AlSo4) in the sintering at $1600 \mathrm{o}$, the result is then milled into three

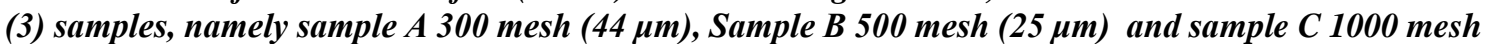
$(12 \mu \mathrm{m})$. Observation results, if the samples are heated to 1000 , sample C has a high sensitivity (Si) to compare with samples $A$ and $B$ with a ratio of 5.7; 5.4 and 4.8. It was concluded that the substrate material with thesize largest mesh of $1000(12 \mu \mathrm{m})$ had a high thermal resistivity (RT) compared to the low mesh material size, sample A 300 mesh $(44 \mu \mathrm{m})$ and and Sample B 500 mesh $(25 \mu \mathrm{m})$. If implemented in the CO gas sensor model, the result is that sample $C$ with mesh $1000(12 \mu \mathrm{m})$ has a greater thermal sensitivity (ST) than samples $B$ and $A$.
\end{abstract}

Keywords : Ekstraction, Silica Sand, Material Substrate, SiO2, Gas Sensor.

\begin{abstract}
Abstrak
Pasir silika adalah material dari kristal silika (SiO2) dan senyawa lainnya yang mengandung material lain selama proses deposisi, memiliki komposisi gabungan dari $\mathrm{SiO}$, $\mathrm{Fe} 2 \mathrm{O3}, \mathrm{Al2O}, \mathrm{CaO}, \mathrm{MgO}$, dan K2O. Sensitivitas((Si) sensor gas dipengaruhi oleh porositas $(\emptyset)$ permukaan substrat, umumnya substrat material dari sensor gas digunakan alumina (Al2O3) atau dioxside silikon (SiO2). Pada artikel ini dibahas hasil proses sintering pada pasir silika yang bertujuan untuk mendapatkan struktur SiO2 yang baik, pada parameter resistivitas termal (RT). Proses sintering dilakukan pada pasir silika dengan campuran almunium sulfat (AlSo4) pada si sintering pada 1600o, hasilnya kemudian di milling

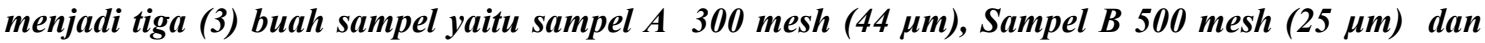
sampel C 1000 mesh (12 $\mu \mathrm{m})$. Hasil pengamatan, jika sampel-sampel tersebut dipanaskan sampai 1000, sampel C memiliki Sensitivity (Si) tinggi untuk dibandingkan dengan sampel A dan B dengan rasio 5,7; 5,4 dan 4,8. Disimpulkan bahwa bahan substrat dengan ukuran mesh terbesar yaitu 1000 (12 $\mu \mathrm{m})$ memiliki resistivitas termal (RT) yang tinggi dibandingkan dengan ukuran bahan mesh rendah, sampel

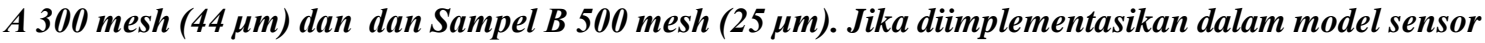
Gas CO, dihasilkan bahwa sample C dengan mesh $1000(12 \mu \mathrm{m})$ memiliki thermal sensitivitas (ST) yang lebih besar dibandingkan dengan sampel $B$ dan $A$.
\end{abstract}

Kata Kunci : Ekstraksi, Pasir Silikat, Material Sibsatrat, Sensor Gas

\section{Pendahuluan}

Material maju adalah material heterostruktur yang disusun oleh dua atau lebih bahan alam yang dikembangkan untuk mendapatkan material baru yang memiliki sifat kelistrikan yang lebih baik, material maju merupakan hasil dari kemajuan ilmu pengetahuan dan teknologi. Kebutuhan akan material maju terus meningkat sejalan dengan majunya teknologi ICT, prediksi kebutuhan akan teknologi material maju ke depan akan sangat menjanjikan, hal ini di- indikasikan 
dengan keadaan dengan berkembangnya komponen elektronika sebagai pendukung IOT (internet of thing), smart sensor dan yang lainnya untuk mendukung implementasi Revolusi 5.O.

Saat ini komponen elektronika dituntut memiliki konsumsi daya yang rendah dan dapat bekerja pada frekuensi Tera herzt. Material heterostruktur dari SilikonGermanium (SiGe) salah satu material maju yang digunakan sebagai material basis pada Heterojunction Bipolar Transistor (HBT), sehingga komponen ini memiliki konsumsi daya yang rendah orde miliwatt dan bekerja pada frekuensi diatas $10 \mathrm{GHz}$. [tossin alamsyah at all]

Menurut buku putih Kemenristek tahun 2010-2020, Penelitian, Pengembangan Iptek Target produksi dan Pengembangan material maju yang diproduksi diutamakan pada material maju berbasis material dasar ; Silikon, Tembaga, Polimer Konduktif dan Electronic Packaging.

Terdapat 3(tiga) hal besar yang perlu dikembangkan yaitu ;

a) Kandungan sumber daya /alam bahan baku komponen material agar ditingkatkan kandungan lokalnya,

b) Meningkatkan sifat dan performa materialnya,

c) Mengubah struktur materialnya.

Nanostructures metal oxide sensor dikelempokan dalam tiga (3) karakteristik yaitu ; conductometric, field effect transistor (FET) and impedometric one[4]. Conductometric sensor bekerja berdasarkan perubahan resistansi dengan pengembamgan teknologi mengarah ke nanoteknologi, MEMS, dan smart material.

Komposit sebagai material sensor memberikan pengaruh yang signifikan pada unjuk kerja sensor. Komposit adalah material hasil rekayasa yang terdiri dari dua atau lebih dari paduan yang sifat kimia dan fisikanya. Dengan adanya perbedaan dari material penyusunnya maka komposit berikatan dengan kuat, dengan penambahan wetting agent, proses sintering adalah salahs atunya.. Hasil penelusuran material komposit yang mengandung silikon sebagai bahan anoda yaitu $\mathrm{MgO}-\mathrm{SiO} 2, \mathrm{AlSiO} 2, \mathrm{SiO} 2$, AlSiCO2, SiAlC, Cr-Si, NiSi2,NiSi, FeSi2, TiN, Si/C, TiC, nano aktif silikon dengan penambahan partikel logam eksternal seperti $\mathrm{Fe}$ dan $\mathrm{Cu}$, juga grafit dan karbon hitam.

Salah cara kerja sensor gas yang dikenal secara umum adalah menggunakan prinsip chemoresistor, yang menggunakan teknologi thick film. Sensor gas berbasis teknologi film tebal menggunakan sepasang elektroda berbentuk interdigital transducers, yaitu sepasang elektroda pararel yang membentuk jari-jari sisir periodik, keduanya saling berhadapan dan saling bertauta, dicetak pada keping substrat (alumina planar) dengan metode screen printing. Sedangkan elemen sensornya (elemen sensitiv) sensornya dicetak dengan metode screen printing juga di atas substrat, konduktifitas pada elektrode akan berubah dengan adanya unsur- unsur kimia (dari gas) yang bekerja pada lapisan sensitif dari bahan semikonduktor (dalam hal ini $\mathrm{SnO} 2$ dan In2O3).

Rancangan Sensor gas dengan struktur akan menghasilkan sensitivitas yang lebih baik, ditunjukkan pada Gambar 2(a) dan (2b) struktur ini lebih dikenal dengan Sensor semikondusktor
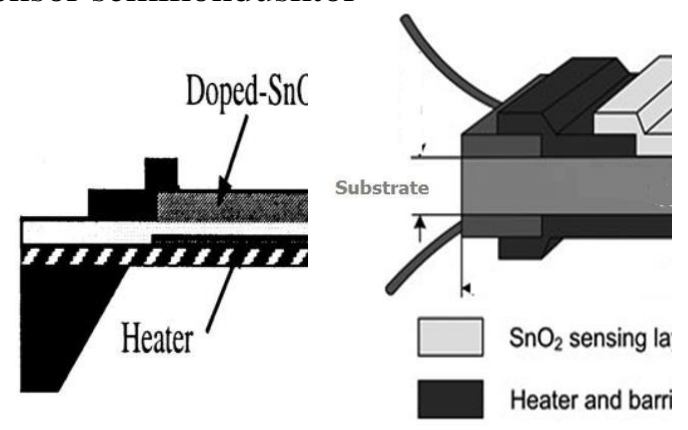
(a). Layout 2D
Model Sensor Gas
[Cwi han at all]
(b). Layout 3D Model Sensor Gas [Cwi han at all]

Gambar 2. Rancangan Sensor Gas 
Tabel dibawah ini menunjukan elemen sensor atau cover sensor yang berfungsi sebagai perangkap gas yang akan di sensing

Tabel 1. menunjukkan elemen dan material subatrat dari sensor gas.

\begin{tabular}{ccc}
\hline No. & $\begin{array}{c}\text { Elemen } \\
\text { sensor/ } \\
\text { Cover sensor }\end{array}$ & Gas yang dideteksi \\
\hline 1. & $\mathrm{SnO} 2$ & $\mathrm{H} 2, \mathrm{CO}, \mathrm{NO} 2, \mathrm{H} 2 \mathrm{~S}, \mathrm{CH} 4$ \\
2. & $\mathrm{TiO} 2$ & $\mathrm{H} 2, \mathrm{C} 2 \mathrm{H} 5 \mathrm{OH}, \mathrm{O} 2$ \\
3. & $\mathrm{FeO} 3$ & $\mathrm{CO}$ \\
4. & $\mathrm{Cr} 1.8 \mathrm{Ti0} 0 \mathrm{O} 3$ & $\mathrm{NH} 3$ \\
5. & $\mathrm{WO} 3$ & $\mathrm{NO} 2, \mathrm{NH} 3$ \\
6. & $\mathrm{In} 2 \mathrm{O} 3$ & $\mathrm{O} 3, \mathrm{NO} 2$ \\
7. & $\mathrm{LaFeO} 3$ & $\mathrm{NO} 2, \mathrm{NOX}$ \\
\hline
\end{tabular}

Dari tabel 1. Di atas menujukkan bahwa material substrat tidak berpengaruh pada target gas yang dideteksi tetapi akan berpengaruh pada Sensitivitas Sensor, seperti yang telah dilakukan secara eksperimental oleh I. A. Averina et all , 2014 dinyatakan bahwa porous (mesh) nanostructured pada substrat yaitu $\mathrm{SiO} 2$ dan - $\mathrm{SnO} 2$ sol-gel films berpengaruh pada Sensitivitas. [6] Zhan Z, dkk., 2013.menyatakan bahwa dengan memodifikasi material Substrat dapat meningkatkan kinerja Sensor CO, lebih sensitiv dengan thermal yang stabil. Jadi artikel ini menjelaskan pengaruh pada material substrat $\mathrm{SiO} 2$ dari hasil proses sintering, dengan ukuran porositas (mesh) yang bervariasi , terhadap Sensitivitas $((\mathrm{Si})$ sensor gas

\section{Metode Penelitian}

Metode penelitian disini menggunakan metode Kualitatif dengan melakukan kegiatan eksperimental di Laboratorium Teknik Elektro dan Laboratorium di tempat lain yang yang mendukung pelaksanaan penelitian ini.

1. Langkah pertama adalah menyiapkan pasir silkat dengan kemurnian $95 \%$. Pasir ini didapat dari hasil pertambangan di
Cibadak Sukabumi.

2. Langkah kedua menyiapkan arang aktif (carbon active) yang berfungsi sebagai katalis saat pembakaran ,material ini dibeli dari PT. Batraco Bandung.

3. Langkah ketiga menyiapkan Tawas Butek (Al2SiO4) material ini sebagai pembentukan komposit $\mathrm{A} 12 \mathrm{SiO} 2$,material ini dibeli dari PT. Batraco Bandung.

4. Langkah keempat adalah mengabungkan ketiga material tersebut dengan komposisi $(70 \%$, $20 \%$ dan 10\%) komposisi ini untuk kemudian dilakukan proses sintering $1600{ }^{\circ} \mathrm{C}$.

5. Membakar/mensintering matrial campuran tersebut selama 2 jam pada Temperatur 1400-1600 derajat celcius, kegiatan ini dilaksanakan di Balai Besar Keramik, Bandung.

6. Menghaluskan / milling material hasil sintering menjadi 300 mesh, 500 mesh dan 1000 mesh.

7. Melakukan Pengukuran SEM dan EDS untuk material tersebut, SEM bermaksud meliha porositas, dan EDS mengamati unsur yang ada pada material tersebut. Pelaksanaan pengukran di laksanakan di lab. Fisika ITB.

8. Mengukur properties kelistrikan material tersebut.

9. Merancang model Sensor Gas.

Flow chart dari aktifitas pengambilan sample adalah sebagai berikut : 


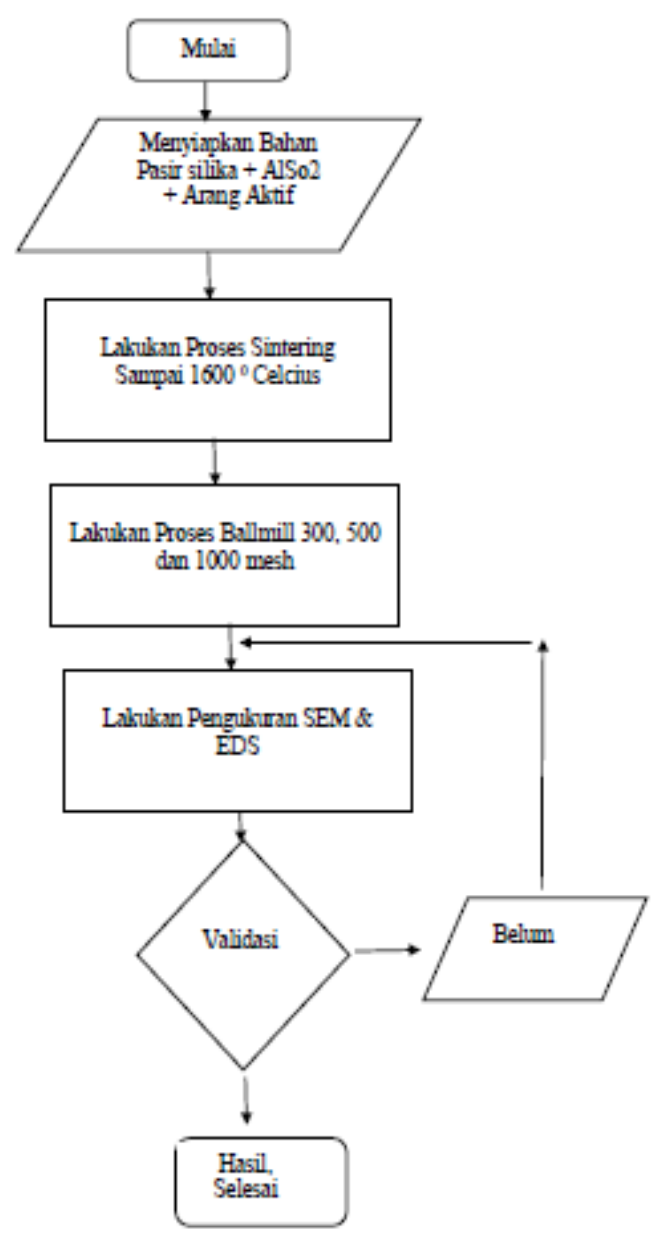

Gambar 3. Flowchart Kegiatan Penelitian.

\section{Hasil Dan Pembahasan}

Dari hasil metodologi pelaksanaan kegiatan penelitian hasil yang dicapai adalah ketersediaan subtrat dari $\mathrm{SiO} 2 / \mathrm{AlSiO} 2$ dengan mesh yang bevariasi serta hasil pengukuran pembacaan SEM dan EDS. Pengukuran Sem dan EDS dari 6 (buah) sample yang tersedia, pengukuran Scanning Electron Microscopy (SEM) menggunakan alat FEI INSPECT S50 dengan tegangan $10.000 \mathrm{kV}$ dan perbesaran 1.500x. Untuk mendapatkan material komposite $\mathrm{AlSiO} 2 / \mathrm{SiO} 2$, perlu dibutuhkan material pasir silica $95 \%$, carbon aktif dan tawas butek (Alum) atau AlSO4. Fungsi dari carbon aktif sebagai katalis saat disintering sedangkan penambahan tawas butek (Alum) sebagai tuning pengatur konduktifitas listrik. Ketiga material tersebut kemudian dicampur dan dipadatkan serta dipanaskan (dibakar) dalam suhu 1600 derajat celcius selama dua jam. Untuk selanjutnya material hasil pembakaran atau sintering dihaluskan sampai memiliki ukuran Mesh 300 44 um, Mesh 500 25 um, dan Mesh 1000 12 um.

Material $\mathrm{SnO} 2$ digunakan sebagai elemen sensor yang langsung berhubungan dengan gas yang akan dideteksi adalah CO. Bila elemen $\mathrm{SnO} 2$ dipanaskan pada suhu tinggi tertentu di udara, oksigen akan teradsorpsi pada permukaan kristal dengan muatan negatif . Elektron-elektron donor pada permukaan kristal ditransfer ke oksigen teradsorpsi, sehingga menghasilkan suatu lapisan ruang bermuatan positip. Akibatnya potensial permukaan terbentuk, yang akan menghambat aliran elektron. Di dalam sensor, arus listrik mengalir melalui bagian-bagian penghubung (batas butir) kristal kristal mikro SnO2. Hasil kajian literatur sebelumnya bahwa sensor gas dengan struktur $\mathrm{SiO} 2 / \mathrm{SnO} 2$ memiliki selektivitas yang baik khususnya untuk gas karbon monoksida. Model Sensor dirancang mempunyai parameter fisik antara lain, elemen atau tudung berbahan $\mathrm{SnO} 2$ ketebalan sekitar 10 $\mathrm{nm}$, Substrat atau base elemen $\mathrm{AlSiO} 2$, tebal $2.5 \mathrm{~mm}$, luas permukaan $125 \mathrm{~mm}^{2}$, terdiri tiga (3) sample yaitu (A) Mesh 300, (B)500 dan (C) 1000. Jenis gas yang digunakan pada uji coba adalah $\mathrm{CO}$ (Karbon monoksida).

Gambar 4(a), 4(b) berikut merupakan proses sintering dan proses ballmil untuk mendapatkan sampe A,B dan $\mathrm{C}$ sesuai untuk selanjutnya dikuri SEM dan EDS nya. 


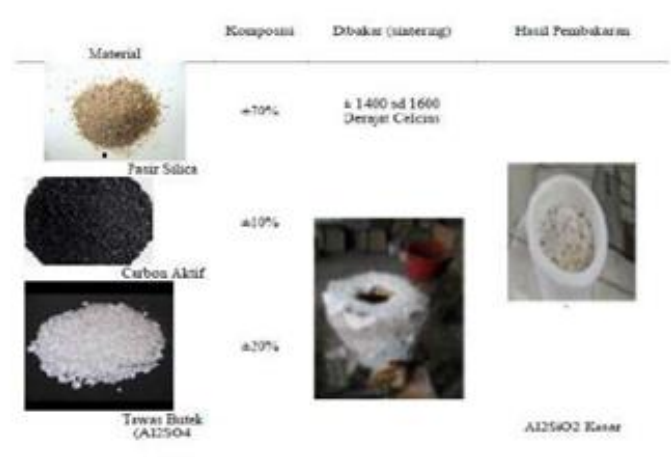

Gambar 4(a). Proses pelaksanaan sintering di Balai Besar Keramik Bandung.

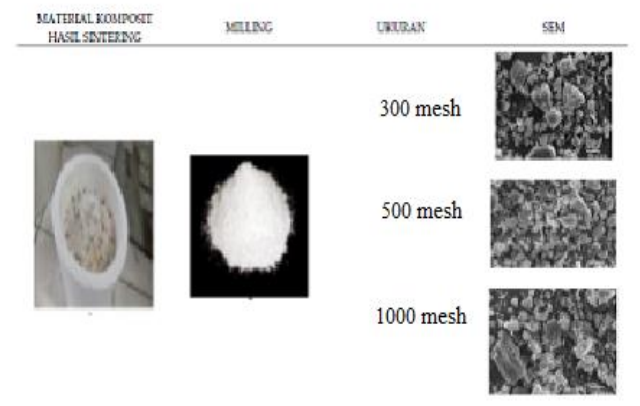

Gambar 4(b). Hasil Proses ballmill dan pengukuran SEM dan EDS.

\section{Hasil Pengujian SEM dan EDX}

Pengujian SEM (Scanning Electron Microscope) dan EDS (Energy Dispersive $\mathrm{X}$-Ray) pada penelitian ini untuk melihat penggambara struktur lapisan dan untuk mendeteksi Silikon Dioksida ( $\mathrm{SiO} 2)$ pada spesimen yang diuji. Selain itu dengan EDX juga dapat mengetahui unsur - unsur apa saja yang ada pada material ini.

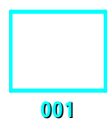

Gambar 4(c). Mikrograf SEM Sample C

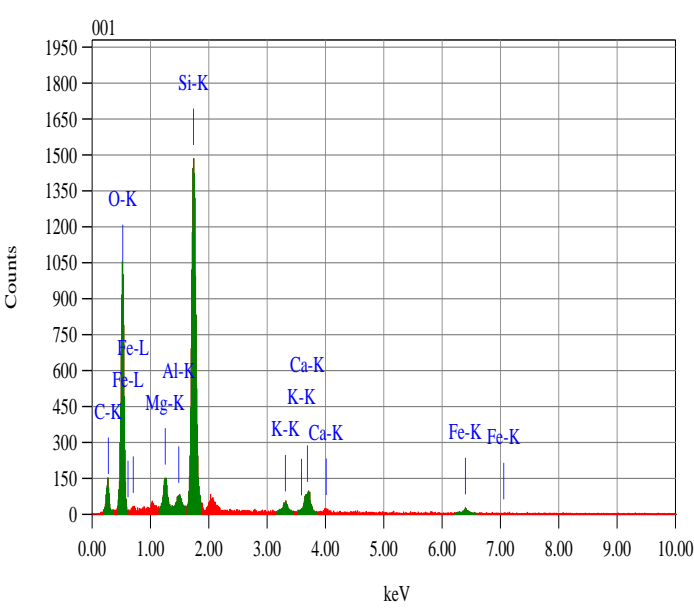

Gambar 4(d). Sample C Pembacaan EDS

Gambar 4(c), menunjukan hasil pemindaian dengan SEM pada sample $\mathrm{C}$ dengan perbesaran 1000 kali. Pada perbesaran ini didominasi oleh material $\mathrm{SiO}$, dan material ikutannya antara lain :

\begin{tabular}{lcccc}
\hline No. & Parameter & $\begin{array}{c}\text { Mesh- } \\
\mathbf{1 0 0 0}\end{array}$ & $\begin{array}{c}\text { Mesh- } \\
\mathbf{5 0 0}\end{array}$ & $\begin{array}{c}\text { Mesh } \\
\mathbf{- 3 0 0}\end{array}$ \\
\hline 1. & \multirow{2}{*}{ kEV } & $\begin{array}{c}0,27- \\
6.2\end{array}$ & $\begin{array}{c}0.277- \\
2,48\end{array}$ & $\begin{array}{c}0,52- \\
1,74\end{array}$ \\
\hline 2. & massa & $\begin{array}{c}52,- \\
0,24\end{array}$ & $7,0-58$ & $\begin{array}{c}61.42- \\
38,5\end{array}$ \\
\hline 3. & Error & $\begin{array}{c}0,69- \\
0,12\end{array}$ & $0,81-$ & 0,15 \\
\hline 4. & Atom & $0,15-$ & 0,32 \\
\hline 5. & C-K & 9,7992 & 1.7283 & - \\
\hline 6. & O_K & 43,82 & 48.2010 & 49 \\
\hline 7. & Mg_K & 2,49 & 5.4342 & - \\
\hline 8. & Al-K & 0,98 & & - \\
\hline 9. & Si-K & 36 & 44.6365 & 50,4 \\
\hline 10. & K-K & 1,7 & & - \\
\hline 11. & Ca-K & 4,4 & & - \\
\hline & Fe-K & 2,2 & & \\
\hline & Total & & & \\
\hline
\end{tabular}

Dari tabel tersebut dapat diamati untuk mesh yang besar material yang yang terbca cukup banyak seperti, $\mathrm{C}, \mathrm{O}, \mathrm{Al}, \mathrm{Mg}, \mathrm{Si}, \mathrm{K}$. Ca dan $\mathrm{Fe}$, dibanding dengan mesh yang kecil, tetapi di domiansi Si dan O. 
Untuk selanjutnya dilakukan pengukuran thermal konduktifitas dari ketiga sample tersebut, hasilnya dapat ditunjukan pada grafik Gambar 5 di bawah ini. Dari grafik tersebut menunjukkan material dengan nilai mesh 1000 (sample A) memiliki thermal konduktivitas yang lebih tinggi disusul dibanding dengan nilai mesh 500 (sampel B), dan mesh 300 (sampel A). Pada pengukuran ini tegangan pada heater berkisar dari 3 Volt sampai 15 Volt, saat tegangan heater 11 Volt, material memiliki temperatur $65^{\circ} \mathrm{C}$ sampai $75^{\circ} \mathrm{C}$, untuk selanjutnya naik secara proporsional.

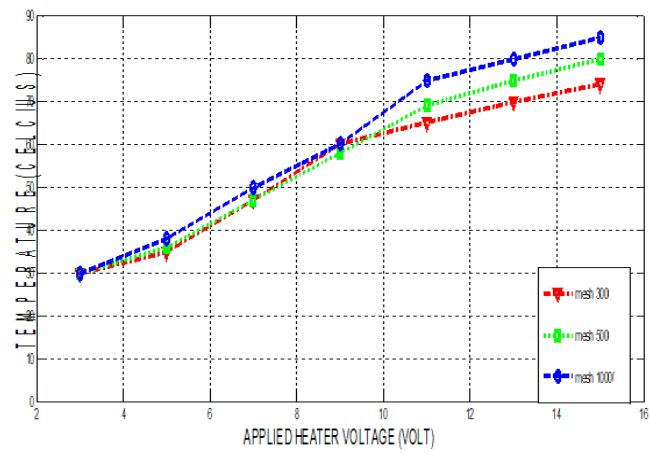

Gambar 5. Temperatur vs Tegangan Heater

Dari grafik Gambar 5 juga diamati , temperatur terhadap tegangan heater didapatkan bahwa substrat dengan ukuran mesh yang besar 1000 mesh (sample C) memiliki capaian Temperatur yang tinggi dibanding mesh 300 dan 500 ( sample B dan A), dengan Rasio 5,7; 5,4 dan 4,8, data ini diambil saat tegangan heater diatas 11 Volt. Berdasarkan dari data tersebut dapat disimpulkan bahwa material substrat dengan ukuran mesh yang besar akan berbanding lurus dengan nilai thermal konduktivitasnya.

Jika diimplementasikan pada model sensor dengan $\mathrm{SnO} 2$ sebagai elemen sensor dengan gas karbon monoksida (CO) sebagai gas yang diuji maka hasilnya dapat ditunjukkan pada grafik Gambar 6.

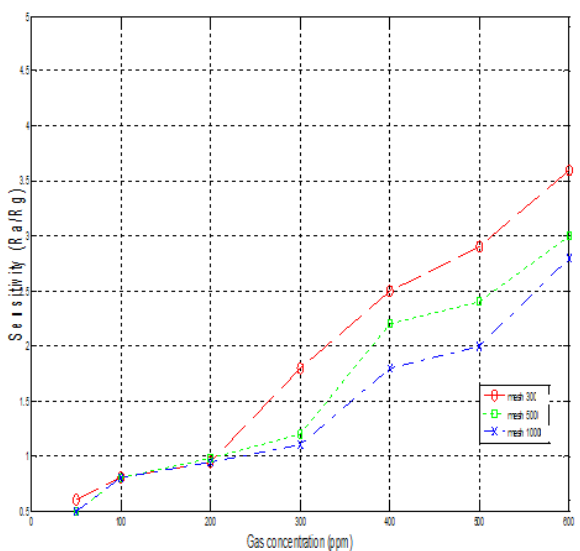

Gambar 6. Respon Senstsitivitas terhadap gas concentrasi

Pengujian sentivitas diterapkan pada gas karbon monoksida (CO), besaran sensitivitas dinyatakan rasio $\mathrm{Ra}$ (resistivity electricity in the air) terhadap $\mathrm{Rg}$ (resistivity electricity when sensor measured gas), . [Chenjai lii at all]. Hasilnya menunjukkan, bahwa sensor dengan substrat mesh 1000 (sample A) memiliki Sensitivity besar yaitu 0.0055 $\Omega /$ ppm, sedangkan untuk ukuran mesh 500 dan 300 ( sample B dan C) nilai Sensitivitas (S) adalah, $0.00455 \Omega / \mathrm{ppm}$, dan $0.0041 \Omega /$ ppm. Dari kedua pernyataan dapat disimpulkan bahwa Temperatur dan Sensitivitas pada sensor Gas, adalah proporsional dengan ukuran mesh material pada substratnya.

\section{Kesimpulan}

Material SiO2 dengan ukuran 1000 mesh memiliki capaian temperatur yang tinggi dibanding mesh 500 dan 300, dengan nilai rasio 5,7 ; 5,4 dan 4,8. Keadaan ini berpengaruh pada sentivitas . Subrat dengan mesh 1000 menghasilkan Sensitivitas $0.0055 \Omega / \mathrm{ppm}$, sedangkan untuk ukuran mesh 500 dan 300, menghasilkan nilai Sensitivitas (S) adalah, $\quad 0.00455 \Omega / \mathrm{ppm}$, dan 0.0041 $\Omega /$ ppm. Dari kedua pernyataan tersebut dapat disimpulkan bahwa Temperatur (RT) dan Sensitivitas (Si) Sensor gas , 
signifikan dengan ukuran mesh material pada substratnya.

\section{Saran}

Penelitian ini perlu dikaji ulang lagi untuk mendapatkan hasil yang baik, tentunya dengan peralatan yang lebih presisi.

\section{Ucapan Terima Kasih}

Disampaikan terimakasih kepada DRPM Kemenristek Dikti yang telah memberikan niaya untuk Penelitian Sensor, dengan material dari Pasir Silika yang diambil dari sumber alam di sekitar Jawa Barat.

\section{Daftar Pustaka}

[1] Kementrian Riset dan Teknologi, “ Buku Putih, Penelitian, Pengembangan dan Penerapan Iptek 2005 -2025 Teknologi Material Maju”, 2005.

[2] Tossin Alamsyah, E Shintadewi Julian, 2016 ." Rekayasa Silicon dan Germanium Sebagai Material Heterostruktur Pada Basis Heterojunction Bipolar Transistor Silicon-Germanium (SiGe-HBT) “ Laporan Penelitian Hibah Kompetensi, P3M Politeknik Negeri Jakarta.

[3] Jacob Praden , 2004"Handbook of Modern Sensor, Physics, Design and Aplication" Third Edit ion, Springer-Verlag New York Berlin Heidelberg,

[4] Tossin Alamsyah, Endang Saepuddin 2017 ." Rekayasa Silicon Sand (Pasir silica) sebagai dasar Sensor Gas.. " Laporan Penelitian PUPT , P3M Politeknik Negeri Jakarta.

[5] P. Song1,2, Z-J. Peng1, Y-L. Yue2, H. Zhang2*, Z. Zhang2, Y-C. Fan3 ",2015 "Mechanical properties of silicone composites reinforced with micron- and nano-sized magnetic particles,", eXPRESS Polymer Letters Vol.7, No.6 (2013) 546-553
[6] Available online at www.expresspolymlett.com,

[7] Mohammad Pourabas1, Mehdi Ghobeiti Hasab2,*, Ali Heidary Moghadam3, 2016, " Investigating the properties of $\mathrm{Al}-\mathrm{SiO} 2$ composite fabricated by the powder metallurgy method." Department of Mechanical Engineering, Dezful Branch, Islamic Azad University, Dezful, IranDepartmen Journal of Energy Conversion, Vol. 2, No.

[8] Virginia Semiconductor, 2012 “ The General Properties of Si, Ge, SiGe, SiO2 and Si3N4" 1501 Powhatan Street, Fredericksburg, VA 22401-4647 USA Phone: (540) 373-2900, FAX (540) 371-0371 www.virginiasemi.com, tech@ virginiasemi.com

[9] A A Ponomareva1, 2, V A Moshnikov1 and G Suchaneck2,2012," Mesoporous sol-gel deposited $\mathrm{SiO} 2-\mathrm{SnO} 2$ nanocomposite thin films," IOP Conf. Series: Materials Science and Engineering 30 (2012).

[10] Chi-Hwan Han 1, Sang-Do Han 1, * and S. P. Khatkar 2, 2006," Enhancement of H2-sensing Properties of F-doped SnO2 Sensor by Surface Modification with SiO2," sensors ISSN 1424-8220@ 2006 by MDPIhttp://www.mdpi.org/sensors.

[11] Guy Tournier, Christophe Pijolat,2005 "Selective _lter for $\mathrm{SnO} 2$ based gas sensors: application to hydrogen trace detection." https://hal.archives-ouvertes.fr/hal00009018

[12] Sun Y, Hu M, Zhou Z,2011 " Effect of $\mathrm{SiO} 2$ nanoparticles doped thick film $\mathrm{ZnO}$ gas sensor" Chinese Journal of Sensors and Actuators, vol. 24, issue 6

[13] Fedorenko et al. Nanoscale Research Letters (2017) , "Semiconductor Gas Sensors Based 
on $\mathrm{Pd} / \mathrm{SnO} 2$ Nanomaterials for Methane Detection in Air "** Correspondence: georgf@ukr.net This work was presented at NANO 2016, 24-27 August, Lviv, Ukraine. Taras Shevchenko National University of Kyiv,

[14] George F. Fine, Leon M. Cavanagh, Ayo Afonja and Russell Binions, "Metal Oxide Semi-Conductor Gas Sensors in Environmental Monitoring", sensors ISSN 14248220

www.mdpi.com/journal/sensors,

[15] Chenjia Li, Meng Lv, Jialin Zuo and Xintang Huang," SnO2 Highly Sensitive CO Gas Sensor Based on Quasi-Molecular-Imprinting Mechanism Design," sensors ISSN 1424-8220

www.mdpi.com/journal/sensors, Sensors 2015, 15, 3789-3800; doi:10.3390/s150203789

[16] S. B. Dhannasarea , S. S. Yawaleb , S.B.Unhalec , and S.P. Yawaleb," Application of nanosize polycrystalline $\mathrm{SnO} 2-\mathrm{WO} 3$ solid material as CO2 gas sensor", Revista Mexicana de F' '1sica 58 (2012) 445-450 DICIEMBRE 2012

[17] J. Wo"llensteina, *, M. Burgmairb , G. Pleschera , T. Sulimab , J. Hildenbranda , H. Bo"ttnera , I. Eiseleb," Cobalt oxide based gas sensors on silicon substrate for operation at low temperatures," a Department of Microsensors, Fraunhofer Institute of Physical Measurement Techniques, Heidenhofstrasse 8, D-79110 Freiburg, Germany b Institute of Physics, Universita"t der Bundeswehr München, 85577 Neubiberg, Germany, Sensors and Actuators B 93 (2003) 442-448, 0925-4005/03/\$ - see front matter \# 2003 Elsevier Science B.V. All rights reserved. doi:10.1016/S09254005(03)00168-0
[18] M De Salve1, G Monnil and B Panella1" Horizontal Air-Water Flow Analysis with Wire Mesh Sensor," 6th European Thermal Sciences Conference (Eurotherm 2012) IOP Publishing.

[19] Sri Agustini Sulandari, Lely Susita Dwi Murwani, "Studi Fabrikasi Isolator Silikon Dioksida (Sio2) Berbasis Lapisan Tipis Menggunakan Teknik Plasma Glow Discharge" Jurnal Fisika Indonesia No: 50, Vol XVII, Edisi Agustus 2013 ISSN : 1410-2994 